\title{
Biological Sciences Tutorial: Freeze-fracture, Deep-etch and 3D Anaglyphs
}

\author{
Robyn Roth $^{1}$
}

1. Washington University School of Medicine, Center for Cellular Imaging, St. Louis, MO

The advent of freeze-fracture electron microscopy in the late 1950's provided a major breakthrough for cell biologists, enabling en face views of cell membranes and membrane leaflets ${ }^{1}$. Continued developments through the 1960's and 70's featured ultrafast freezing techniques ${ }^{2}$ that complemented parallel advances in metal coating units ${ }^{3}$. Rapidly frozen specimens, subjected to etching and rotary metal application gave birth to "deep-etching", rendering detailed replicas of cell surfaces, organelles, cytoskeletons, and macromolecules, with $\sim 1-2 \mathrm{~nm}$ resolution and striking three-dimensional perspective $^{4,5}$.

Each wave of imaging advancement, whether in sample preparation, LM, TEM, SEM, CryoEM, ultramicrotomes, and molecular biology, bring with it an exciting new twist to the understanding of biological processes. Enjoying it's $60^{\text {th }}$ year of invention, freeze-fracture deep-etch EM holds up as a robust method of sample preparation, that is complementary to other contemporary approaches. The procedure is relatively quick, start to final imaging is typically a work day ${ }^{6}$. Recent use of Tokuyasu sectioning techniques, FRIL and STORM have given freeze-fracture a new life, providing additional cytochemical information to ultrastructure that was once elusive $e^{1,7-9}$. This tutorial will provide an overview of today's freeze-fracture deep-etch EM technique.

\section{References:}

[1] Severs, N. J. Nature Protocols 2, (2007). 547

[2] Van Harreveld, A. \& Crowell, J. Anat. Rec. 149, (1964), 381.

[3] Moor, H. \& Mühlethaler, K. The Journal of Cell Biology 17, (1963), 609.

[4] Heuser, J. E. \& Salpeter, S. R. The Journal of Cell Biology 82, (1979), 150.

[5] Heuser, J. E. Methods Cell Biol. 22, (1981), 97.

[6] Heuser, J. E. Biomedical Reviews 12, (2001), 11.

[7] Tokuyasu, K. T. \& Singer, S. J. The Journal of Cell Biology 71, (1976), 894.

[8] Dinchuk, J. E., Johnson, T. J. \& Rash, J. E. J Electron Microsc Tech 7, (1987), 1.

[9] Suleiman, H. et al. Elife 2, (2013), e01149. 

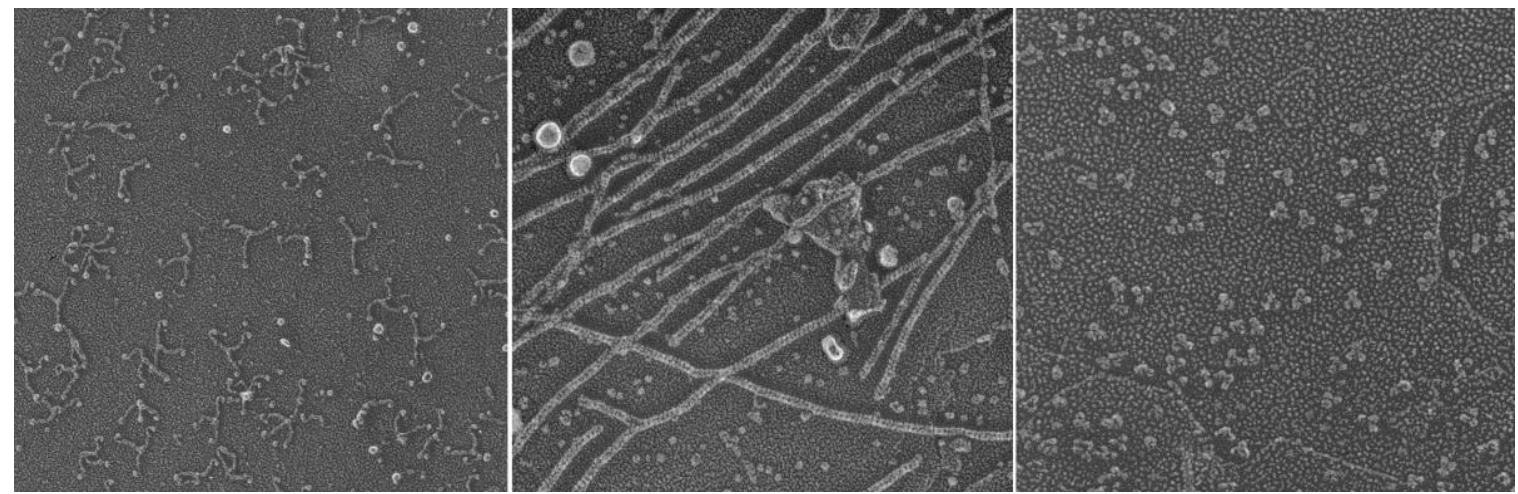

Figure 1. Purified molecules on mica. Freeze-fracture and deep-etch.

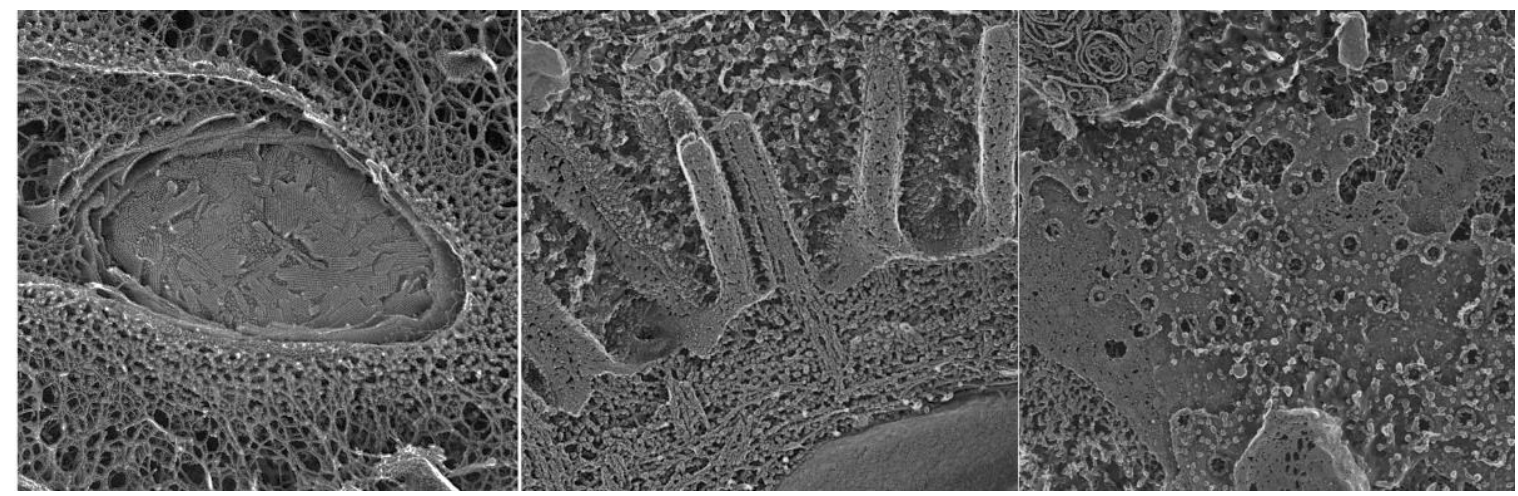

Figure 2. Freeze-fracture deep-etch of cell pellets and tissues.
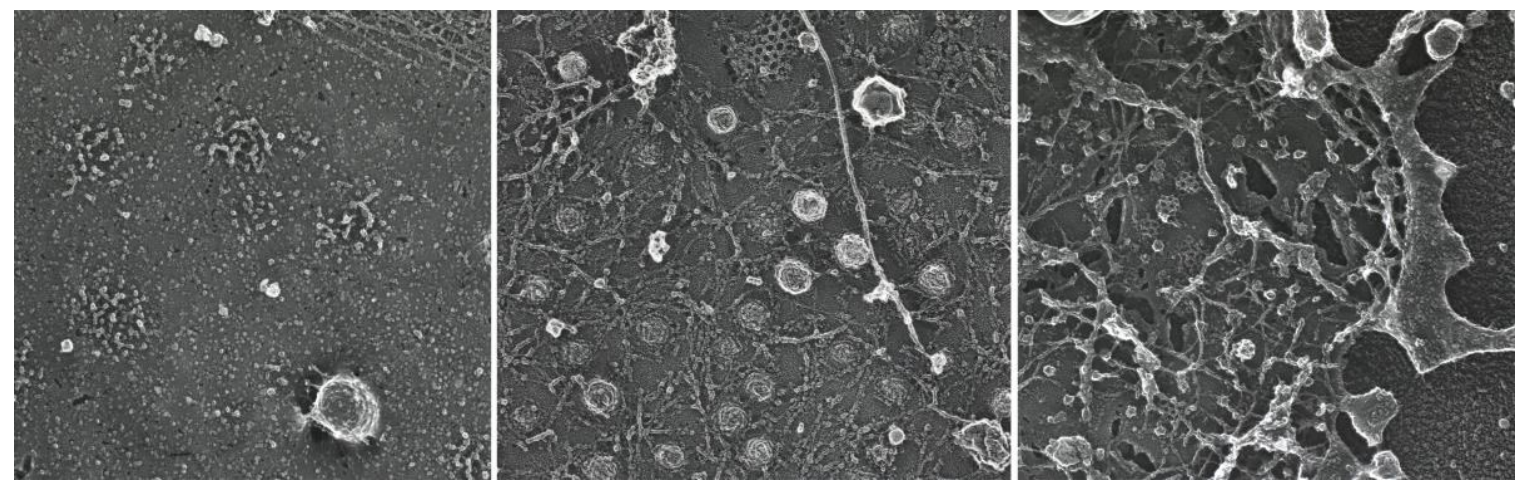

Figure 3. Freeze-dried preparations of sonicated cell culture. 